\title{
Female reproductive tract
}

Mucosal surfaces of the female reproductive tract contain a variety of antimicrobials that provide the first line of defense against bacteria involved in the development of bacterial vaginosis (BV).

\section{Bacterial vaginosis}

Microbiological analysis of BV has shown Gardnerella vaginalis to be a keystone species in BV development. However, G. vaginalis colonization does not always lead to BV. Over the last decade, phenotypic and genotypic studies have suggested the existence of strains variants.

\section{Goal of study}

Our study aimed to investigate the effect of lysozyme, lactoferrin, and $\beta$-defensin 2 on $G$. vaginalis strains isolated from healthy women and women with BV, in order to highlight virulence differences.

\section{Results}

Table 1. G. vaginalis genotyping based on clade classification system; and minimum inhibitory concentration (MIC) of lysozyme (LYS), lactoferrin (LF), and human $\beta$-defensin 2 (HBD2) for planktonic cells of $G$. vaginalis isolates

\begin{tabular}{|c|c|c|c|c|}
\hline \multirow[t]{2}{*}{ Bacteria } & \multirow{2}{*}{$\begin{array}{c}\text { Clade } \\
\text { distribution }\end{array}$} & \multicolumn{3}{|c|}{ MIC range } \\
\hline & & LYS ( $\mu \mathrm{g} / \mathrm{mL})$ & $\mathrm{LF}(\mu \mathrm{g} / \mathrm{mL})$ & HBD2 (ng/mL) \\
\hline \multicolumn{5}{|c|}{ non-BV isolates } \\
\hline Gv UM085 & 1 & $>1280$ & $>256$ & $>128$ \\
\hline Gv UM061 & 1 & $>1280$ & $>256$ & $>128$ \\
\hline Gv UM131 & 2 & $>1280$ & $>256$ & $>128$ \\
\hline Gv UM016 & 1 & 1280 & $>256$ & $>128$ \\
\hline Gv UM094 & 4 & $>1280$ & $>256$ & $>128$ \\
\hline Gv UM060 & 1 & $>1280$ & $>256$ & $>128$ \\
\hline Gv UM246 & 1 & [640-1280] & $>256$ & $>128$ \\
\hline \multicolumn{5}{|l|}{ BV isolates } \\
\hline Gv UM067 & 2 & [640-1280] & $>256$ & $>128$ \\
\hline Gv UM121 & 1 & 1280 & $>256$ & $>128$ \\
\hline Gv UM035 & 2 & $>1280$ & $>256$ & $>128$ \\
\hline Gv UM137 & 1 & 1280 & $>256$ & $>128$ \\
\hline Gv UM224 & 4 & $>1280$ & $>256$ & $>128$ \\
\hline Gv UM241 & 1 & $>1280$ & $>256$ & $>128$ \\
\hline Gv UM034 & 4 & [640-1280] & $>256$ & $>128$ \\
\hline
\end{tabular}

\section{Major conclusion}

\section{Methods}

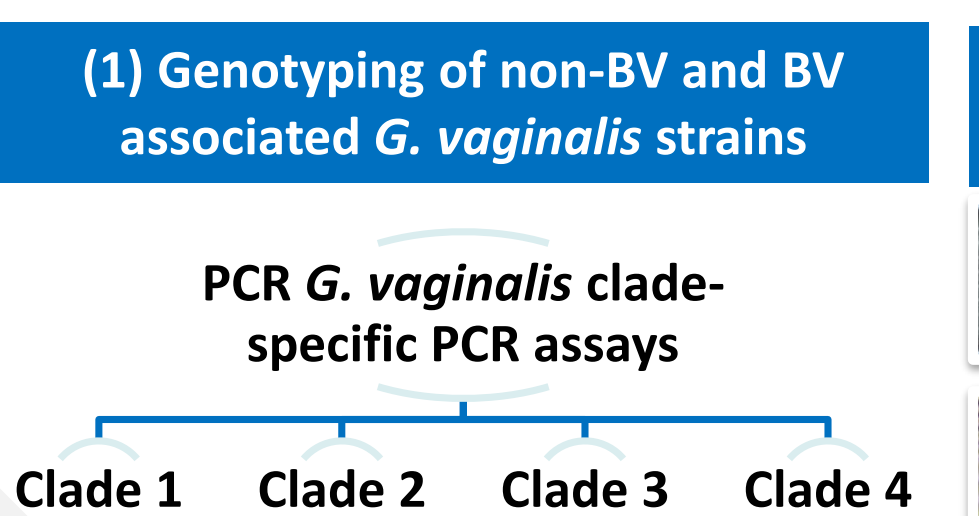

\section{(2) Analysis the effect of LYS, LF and HBD2} on $G$. vaginalis strains

\begin{tabular}{|c|c|c|}
\hline MIC assays & & $\begin{array}{l}\text { Adhesion } \\
\text { assays }\end{array}$ \\
\hline $\begin{array}{l}\text { Biofilm } \\
\text { formation }\end{array}$ & & $\begin{array}{l}\text { Study of } \\
\text { growth kinetics }\end{array}$ \\
\hline
\end{tabular}

The response to the innate immune components was similar between both groups, suggesting that a better adaptation to the host immune components is not a key factor differentiating between isolates from women with $\mathrm{BV}$ and from healthy women.

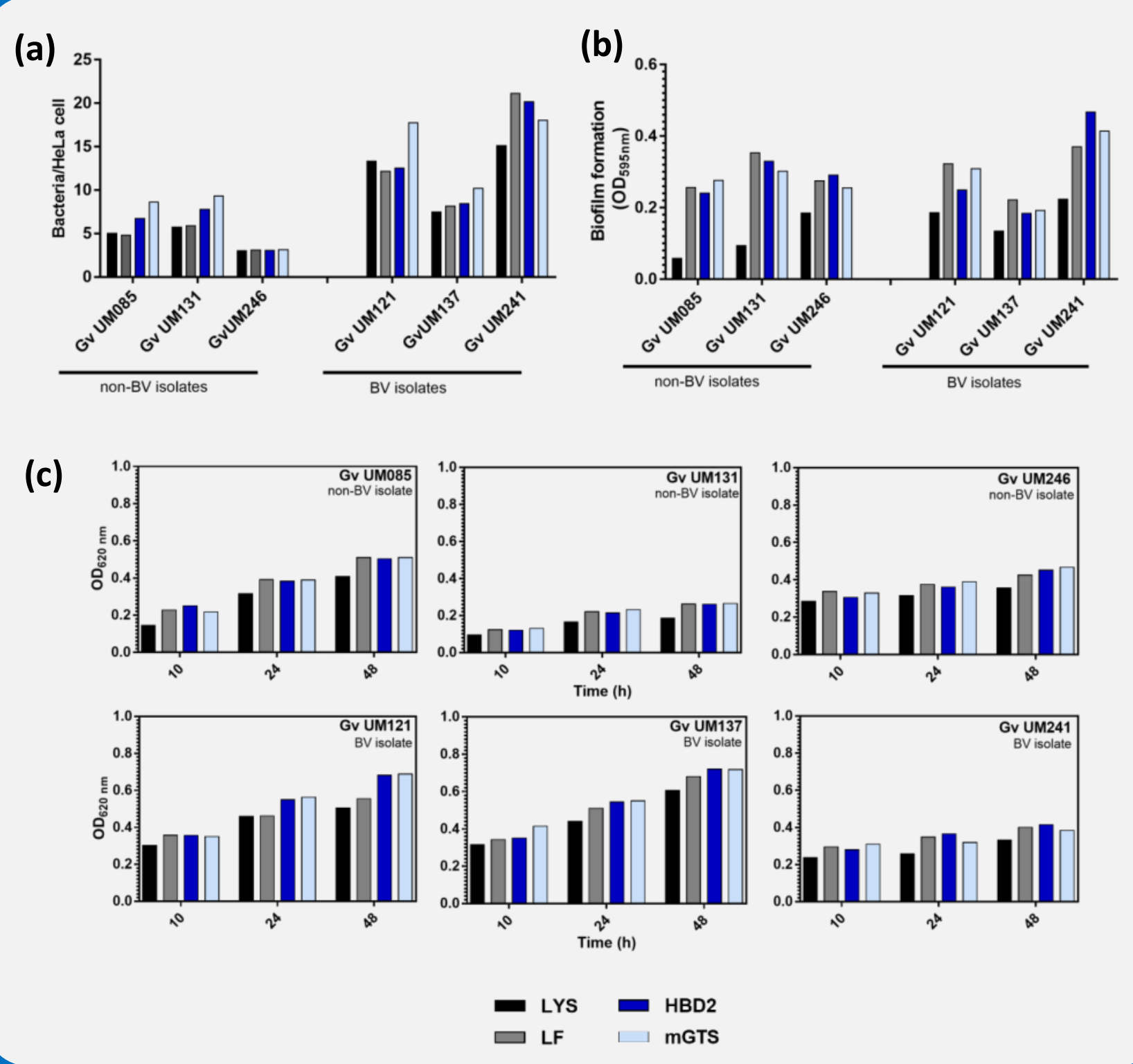

Figure 1. Effect of lysozyme (LYS), lactoferrin (LF), and human $\beta$-defensin 2 (HBD2) on non-BV and BV associated G. vaginalis isolates. (a) Initial adhesion to HeLa cells and (b) biofilm formation and (c) bacterial fitness profile of $G$. vaginalis strains in the presence of physiological vaginal innate immune molecules.
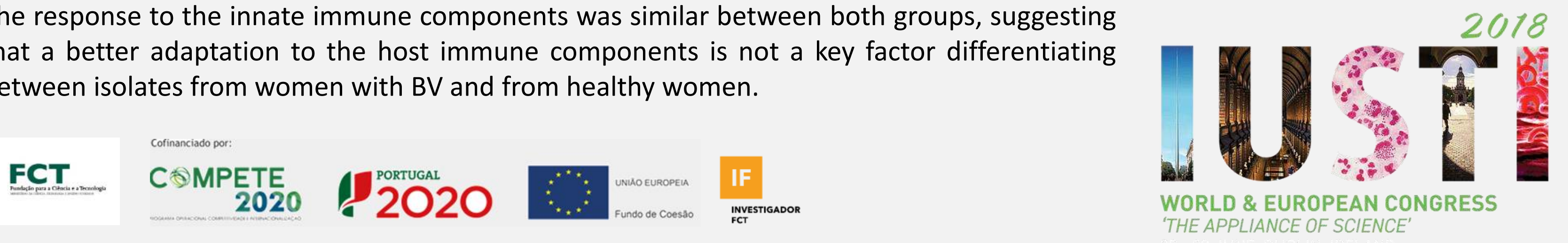